\title{
Diagnóstico laboratorial de hemoglobinas semelhantes à $\mathrm{HbS}$
}

\author{
Laboratorial diagnosis for hemoglobin like HbS
}

\author{
Paula Juliana Antoniazzo Zamaro' \\ Andréia A. Canalli ${ }^{2}$ \\ Wilson Araujo da Silva Júnior ${ }^{3}$ \\ Claudia Regina Bonini Domingos ${ }^{4}$
}

\section{unitermos resumo}

Hemoglobina S

Isoformas de hemoglobina

Diagnóstico laboratorial

A hemoglobina S (HbS) está presente na população brasileira com prevalência variável, dependente dos grupos raciais formadores de cada região. A migração eletroforética em $\mathrm{pH}$ alcalino apresenta similaridade com outras hemoglobinas, e estudos complementares para sua correta caracterização são necessários. No presente estudo objetivamos traçar um fluxograma com as metodologias disponíveis para a caracterização da hemoglobina $S$ e das hemoglobinas que apresentam migração semelhante em $\mathrm{pH}$ alcalino. No período de janeiro a junho de 2000, analisamos amostras de sangue com suspeita de hemoglobina S encaminhadas ao Laboratório de Hemoglobinas da Unesp. Caracterizamos diferentes mutantes e formas interativas com hemoglobina $\mathrm{S}$, por procedimentos eletroforéticos, em variados $\mathrm{pH}$, análises citológicas e testes bioquímicos específicos. Os procedimentos de análise aplicados resultaram em orientação fornecida aos laboratórios de rotina sobre como proceder no diagnóstico laboratorial destas alterações de hemoglobina. Desta forma contribuímos para um melhor conhecimento sobre a variabilidade genética das hemoglobinas em nossa população, auxiliando no acompanhamento clínico e no aconselhamento genético das hemoglobinopatias com fisiopatologia relacionada à alteração.
\end{abstract}

\section{abstract}

The hemoglobin S is presented at Brazilian population with variable prevalence dependent of constitutive racial groups in each region. The electrophoretic migration on alkaline $\mathrm{pH}$ showed similarities with another hemoglobins. Complementary studies to the correct caracterization

becomes necessary. At the present study we aimed make a fluxogram with the avaliable methodologies for the caracterization of hemoglobin $S$ and hemoglobins that present similar migration on alkaline pH. During the period of January to June, 2000, we had analised blood samples with suspicious hemoglobin S sent to the Laboratory of Hemoglobins, Unesp.

Were caracterized different mutants and interative forms with hemoglobin S by electrophoretic procedures on different $\mathrm{pH}$, citologic anlysis and specific biochemical tests. The applyed analitical

procedures result in a guide for the routine laboratories with laboratories with laboratorial diagnostic procedure for these hemoglobin alterations. Thus, we contributed to a better knowledge about genetic variability at the hemoglobins in our population, helping on the clinical attendance and genetic conseling of hemoglobinopathies with relation to physiological alterations. key words

Hemoglobin S

Hemoglobinopathies

Laboratorial diagnostic
1. Mestranda do Programa de PósGraduação em Genética - Ibilce/ Unesp - São José do Rio Preto-SP. 2. Biomédica do Hemocentro Ribeirão Preto-SP.

3. Professor doutor do Laboratório de Clonagem e Biologia Molecular - Hemocentro - Ribeirão Preto-SP. 4. Professora doutora do Laboratório de Cenética das Doenças Hematológicas - Ibilce/ Unesp - São José do Rio Preto-SP. Trabalho desenvolvido no Laboratório de Genética das Doenças Hematológicas - Ibilce/ Unesp - Departamento de Biologia - São José do Rio Preto-SP. 


\section{Introdução}

A hemoglobina é uma proteína composta por quatro globinas, associadas a grupos heme, complexo formado por um átomo de ferro em uma estrutura porfírica. A porção protéica da hemoglobina consiste em dois pares de cadeias polipeptídicas. Nos adultos normais, há duas cadeias alfa e duas cadeias beta, formando a hemoglobina $A$, e duas cadeias alfa e duas delta para a hemoglobina $A_{2}$. Durante o desenvolvimento fetal predomina a síntese de cadeias gama no lugar das cadeias beta, que, associadas às cadeias alfa, originam a hemoglobina fetal ( $\mathrm{HbF})(8)$.

Os genes da globina alfa estão arranjados no cromossomo 16 , e os genes da betaglobina, no cromossomo 11. Cada um dos genes do cluster da globina tem sido seqüenciado, e sua estrutura, estabelecida, além de um número de importantes seqüências regulatórias bem definidas (3). Os elementos promotores agem em cis para o final 5' de cada um dos genes da globina, o TATA e o CCAAT boxes, e os motivos duplicados CACCC. Vários elementos acentuadores têm sido caracterizados. São seqüências distais, as quais aumentam os níveis de transcrição do gene. Há duas seqüências regulatórias: o LCR (região controladora do locus), no cluster do gene beta, marcado por sítios hipersensíveis à DNAse, e o HS (sítio hipersensível), no cluster do gene alfa, similar ao LCR. Estas seqüências, e muitas regiões através do complexo do gene da globina, contêm sítios de ligação para fatores de transcrição específicos para a linhagem eritróide, GATA-1 e NF-E2 e para uma variedade de proteínas de ligação ao DNA ubiquitinosado. O modelo de controle da síntese de globinas mais favorecido sugere que a transcrição dos genes envolve a posição do LCR para cada gene individual, que, junto com uma variedade de fatores de transcrição de ação trans e com a RNA polimerase II, atua para formar um complexo transcricional na região promotora (14).

Um par de genes determina a estrutura da cadeia beta. $\mathrm{Na}$ anemia falciforme, a hemoglobina $S$ é formada pela substituição de um aminoácido na cadeia beta, na posição número seis. $\mathrm{O}$ ácido glutâmico é substituído por uma valina. Ambos os genes responsáveis pela produção da cadeia beta codificam $\mathrm{HbS}$. Neste caso, $\mathrm{HbA}$ não está presente devido à falta de alelo normal de cadeias. Os heterozigotos para $\mathrm{HbS}$ têm um único alelo alterado. O outro gene da cadeia beta codifica uma cadeia beta normal, resultando no traço falciforme. O gene $\beta^{S}$, por estar associado a algumas outras variantes estruturais, como a $\mathrm{HbC}$, resultam em indivíduos com HbSC. A herança com talassemia beta resulta em uma síndrome HbS- $\beta$-talassemia $(11,14)$.

A maioria das hemoglobinas anormais resulta da substituição de um aminoácido por outro em uma das cadeias globínicas. Hemoglobinas C, D-Los Angeles, E e S são exemplo de tal defeito. Destas hemoglobinas anormais provém a base para a classificação das hemoglobinopatias - um grupo de anormalidades hereditárias no qual a produção de hemoglobinas normais é suprimida, em parte ou toda ela, e substituída pela produção de uma ou mais das muitas hemoglobinas variantes $(1,6,8)$.

A hemoglobina $S$ está presente na população brasileira com prevalências variáveis, dependentes dos grupos raciais formadores de cada região. A migração eletroforética em $\mathrm{pH}$ alcalino apresenta similaridade com outras hemoglobinas, e estudos complementares para sua correta caracterização são necessários (2).

A hemoglobina $G$ (Philadelphia) é uma variante de cadeia alfa, com a mobilidade eletroforética semelhante à $\mathrm{HbS}$ em pH alcalino (11).

Métodos de avaliação para a detecção de hemoglobinas anormais incluem teste de solubilidade, eletroforese em pH alcalino e ácido, focalização isoelétrica, eletroforese de cadeias globínicas e cromatografia líquida de alta performance (HPLC). Estas técnicas apresentam vantagens e limitações para a separação de hemoglobinas $(1,4,7)$. No presente estudo objetivamos traçar um fluxograma com as metodologias usuais para a caracterização das falcemias e das hemoglobinas que apresentam migração semelhante em pH alcalino. No período de janeiro a junho de 2000, analisamos amostras de sangue com suspeita de hemoglobina $S$ encaminhadas ao Laboratório de Hemoglobinas da Unesp para caracterizar esta variante e as isoformas com migrações semelhantes.

\section{Material e métodos}

As amostras de sangue utilizadas para a realização deste trabalho foram colhidas com EDTA a 5\% como anticoagulante e enviadas ao Laboratório de Hemoglobinas na Unesp, em São José do Rio Preto (SP), após prévia autorização em termo de consentimento segundo orientação do Comitê de Ética em pesquisa da Unesp. As amostras foram submetidas aos procedimentos laboratoriais padronizados no Laboratório de Hemoglobinas, sendo:

- Testes de triagem:

- resistência globular osmótica em $\mathrm{NaCl}$ a $0,36 \%$, específica para triagem de talassemias (10); 
- análise da morfologia eritrocitária (1);

- eletroforese em pH alcalino (5).

- Testes de confirmação:

- eletroforese em pH ácido (12), utilizando o kit da Cia. Equipadora de Laboratórios Modernos (Celm);

- isoeletrofocalização (6);

- eletroforese de cadeias polipeptídicas (9);

- cromatografia líquida de alta performance (HPLC) (10), com equipamento Variant Bio-Rad e kit betatalassemia heterozigota.

- análises moleculares por PCR-RFLP utilizando os primers $5^{\prime} \rightarrow 3^{\prime}:$ GGC AGA GCC ATC TAT TGC TTA e $\left(5^{\prime} \rightarrow 3^{\prime}\right)$ : ACC TTA GGG TTG CCC ATA AC, para HbS, C e D com as respectivas enzimas Ddel, BseRI e EcoRI.

\section{Resultados}

A co-migração de isoformas de hemoglobinas em eletroforese em $\mathrm{pH}$ alcalino levou-nos a pensar em uma pesquisa mais detalhada, tendo em vista que este procedimento é o mais rotineiramente utilizado em laboratórios.

O Laboratório de Hemoglobinas e o Laboratório de Genética das Doenças Hematológicas da Unesp recebem amostras de sangue para a caracterização de hemoglobinas anormais de diferentes localidades do país. Das amostras que foram submetidas aos procedimentos de triagem, 345 apresentaram migração eletroforética em $\mathrm{pH}$ alcalino na posição da HbS. Foram avaliadas por outras metodologias, onde caracterizamos diferentes isoformas de hemoglobinas, conforme pode ser visto na
Figura 1, utilizando gel de agarose Celm. As amostras que apresentaram perfil semelhante à hemoglobina $S$ em eletroforese alcalina foram submetidas a eletroforese em gel Celm, pH ácido (Figura 2), selecionando o que poderia ser $\mathrm{HbS}$ das hemoglobinas que não apresentavam o padrão esperado.

Pela metodologia de isoeletrofocalização observamos, nestas amostras, a presença da $\mathrm{HbS}$ e de outras variantes como a $\mathrm{HbD}$ e $\mathrm{Hb}$ Lepore, também caracterizadas em nosso estudo. Além destas variantes, identificamos um mutante de cadeia alfa do tipo $G$, por eletroforese de cadeias globínicas.

A cromatografia líquida de alta performance forneceu subsídios adicionais para a caracterização dos mutantes de hemoglobina. Os cromatogramas da Figura 3 evidenciam os tempos de retenção das amostras com suspeita de HbAS, HbAD-Los Angeles, HbA Lepore, HbAG e interação $\mathrm{HbS} / \beta^{+}$-talassemia, analisadas pelo kit

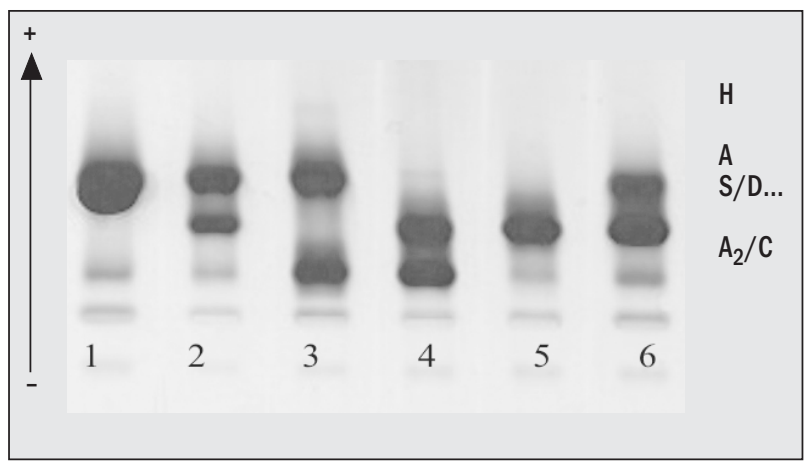

Figura 1 - Eletroforese em gel em $p H$ alcalino, com migração de amostras semelhantes à HbS. 1. HbAA; 2. HbAS; 3. HbAC; 4. HbSC; 5. HbSS;

6. HbS/beta mais talassemia

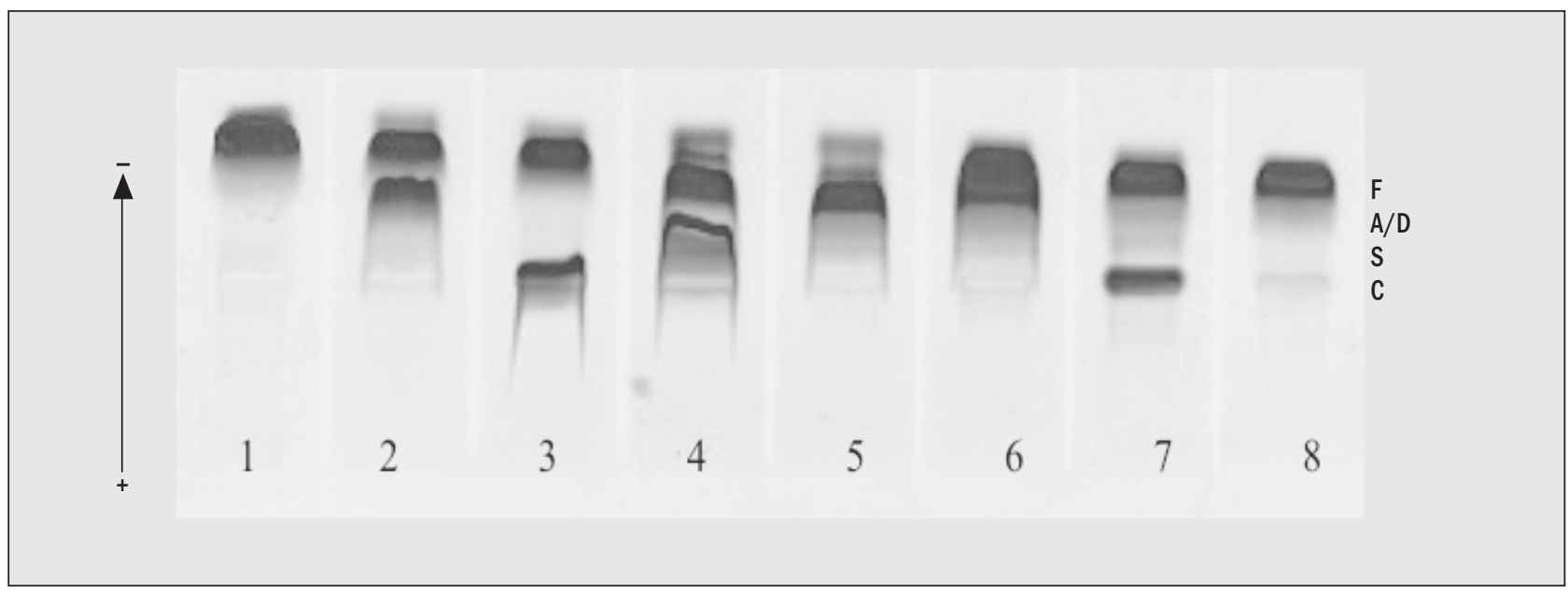

Figura 2 - Eletroforese em gel Celm, em pH ácido, utilizado para caracterização de HbS. 1. HbAA; 2. HbAS; 3. HbAC; 4. HbSC; 5. HbSS; 6. HbAD; 7. HbS/beta mais talassemia; 8. HbA Lepore 

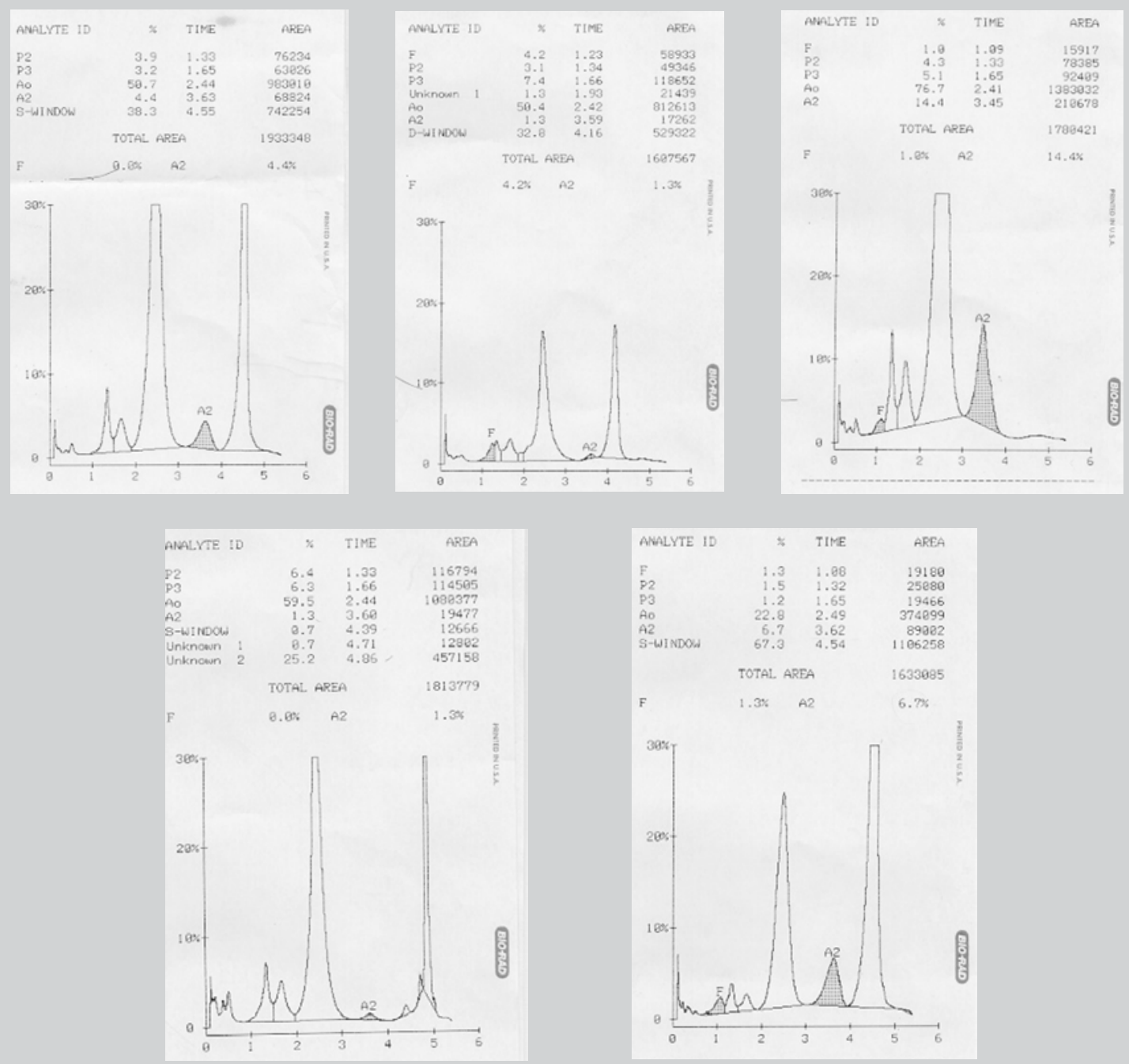

Figura 3 - Cromatogramas de portadores de hemoglobinas anormais com migração semelhante, em eletroforese em pH alcalino, utilizando equipamento Variant II Bio-Rad. 1. HbAS; 2. HbAD; 3. HbA Lepore; 4. HbAC; 5. HbS/beta mais talassemia

betatalassemia no equipamento Variant, da Bio-Rad, sendo que todas apresentaram padrão de migração similar em eletroforese alcalina.

O fluxograma da Figura 4 ilustra os procedimentos laboratoriais sugeridos para a caracterização de variantes de hemoglobinas com traçado eletroforético semelhante à $\mathrm{HbS}$.

Algumas amostras foram submetidas à confirmação do diagnóstico por biologia molecular no Hemocentro de Ribeirão Preto. Realizamos a amplificação do DNA, por primers específicos para cada alteração, e, após análise em mapa de restrição, o produto foi digerido por enzimas que possibilitaram caracterizar os mutantes, fornecendo informações sobre seu genótipo. A Figura 5 ilustra um gel de agarose, com amostras amplificadas e digeridas para $\mathrm{HbS}, \mathrm{HbC}$ e HbD, em diferentes combinações, evidenciadas por revelação com brometo de etídio.

\section{Discussão}

A prevalência do traço falciforme em nossa população é variável, de região para região, seguindo características da formação racial de nossa população (5).

A diversidade genética das hemoglobinas decorrente dos processos de migração nos faz repensar a utilização de metodologias para o diagnóstico de hemoglobinas anormais, muitas vezes feito através do fenótipo. Dados como origens racial e clínica, hematologia, transfusões e status de ferro auxiliam no diagnóstico.

A eletroforese em acetato de celulose, $\mathrm{pH}$ alcalino, amplamente difundida, é uma metodologia que deve ser utilizada como teste de rastreamento inicial para a deteç̧ão de hemoglobinas variantes. Metodologias complementares devem ser realizadas para a caracterização de hemoglobinas com migração semelhante. 


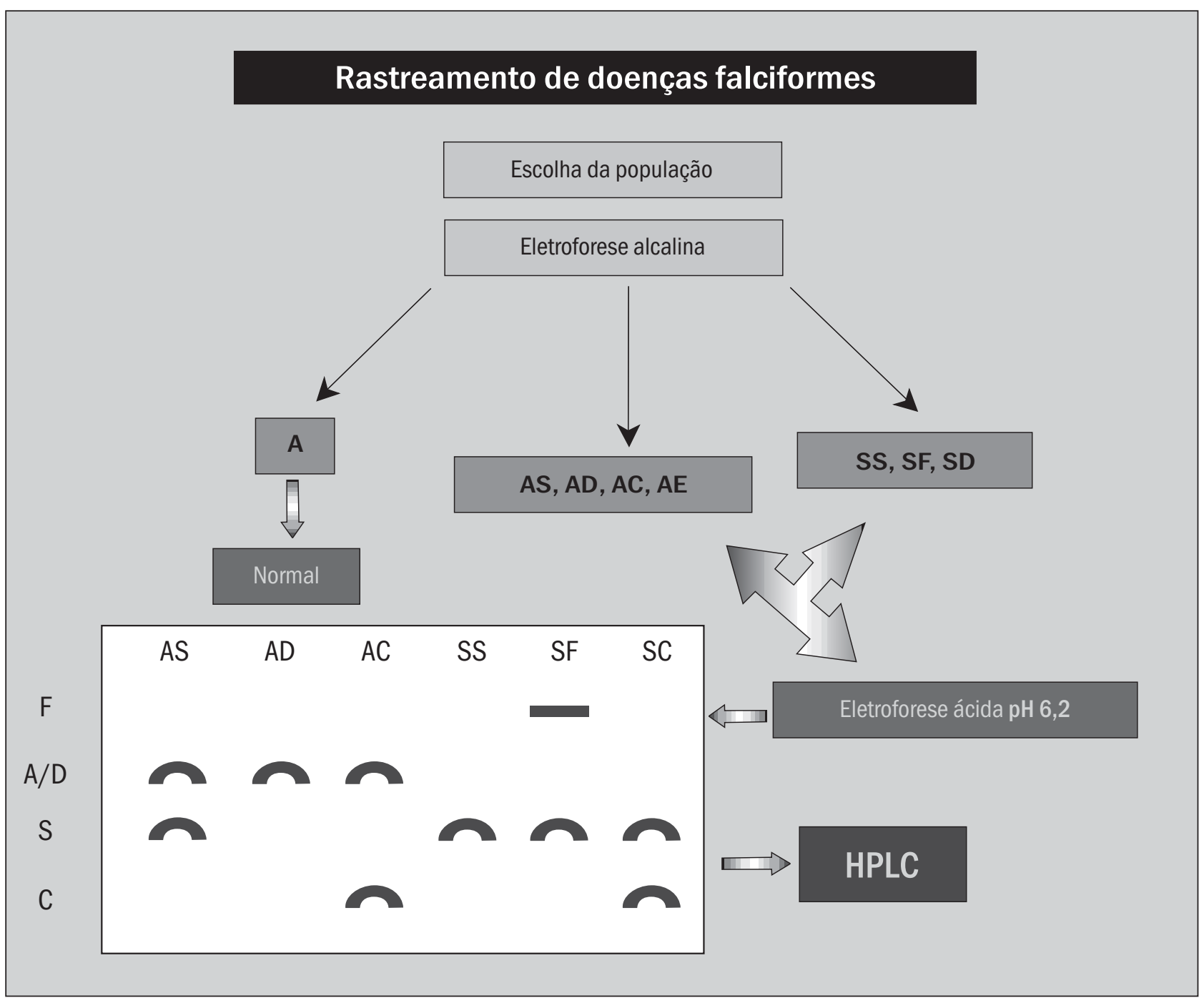

Figura 4 - Fluxograma de análises sugeridas para rastreamento de doença falciforme

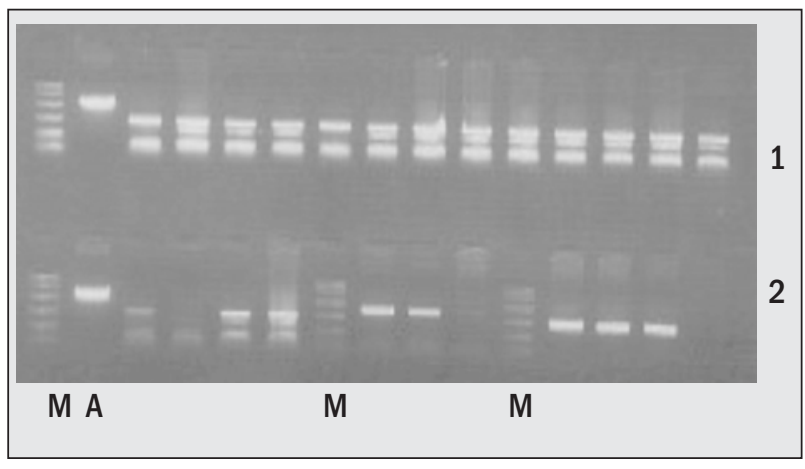

Figura 5 - Gel de agarose com amplificados digeridos. Amostras de $\mathrm{HbS}$ na primeira linha; $H b C$, amostras de 8 a 10 na segunda linha; $H b D$, amostras de 12 a 14 na segunda linha. M: marcador; A: amplificado não-digerido

Nossos resultados mostraram que algumas isoformas de hemoglobina, migrando na posição de $\mathrm{HbS}$ em acetato de celulose ou agarose, em pH alcalino, puderam ser caracterizadas posteriormente como outras variantes. As metodologias adicionais devem ser utilizadas na caracterização do genótipo destas variantes de hemoglobina, possibilitando um diagnóstico preciso da sua expressão.

Os procedimentos de análise aplicados em nosso estudo resultaram em um fluxograma que pode ser útil na orientação para os laboratórios de rotina, em como proceder no diagnóstico laboratorial destas alterações. Desta forma contribuímos para um melhor conhecimento sobre a variabilidade genética das hemoglobinas em nossa população, auxiliando desta maneira o acompanhamento clínico e o aconselhamento genético das hemoglobinopatias com fisiopatologia relacionada.

\section{Conclusões}

Um programa para identificar hemoglobinas anormais deve utilizar metodologia adequada ao correto diagnósti- 
co das diferentes isoformas para efetivo aconselhamento genético e tratamento destas desordens genéticas. A metodologia adequada inclui procedimentos eletroforéticos em diferentes $\mathrm{pHs}$, isoeletrofocalização e HPLC. O treinamento do pessoal capacitado para o diagnóstico laboratorial e o aconselhamento genético é de fundamental importância para o conhecimento das hemoglobinas anormais na população brasileira.

\section{Referências}

I. Bonini-Domingos, C.R. Hemoglobinopatias no Brasil: variabilidade genética e metodologia laboratorial. São José do Rio Preto, 1993. Tese de Doutoramento em Ciências Biológicas. Instituto de Biociências Letras e Ciências Exatas, Universidade Estadual Paulista.

2. Guideline. The laboratory diagnosis of haemoglobinopathies. British.J. Haematol., 101: 783-92, 1998.

3. Honig, G.R. \& Adams III, J.G. Human hemoglobin genetics. Wien: Springer, 1986.

4. Lorey, F. et al. Universal screening for hemoglobinopathies using high-performance liquid chromatography: clinical results of 2.2 million screens. Eur. J. Hum. Genet., 2: 2627I, 1994.

5. Marengo-Rowe, A.J. Rapid electrophoresis and quantitation of haemoglobin on cellulose acetato. J. Clin. Path., 18: 90-192, 1965.

6. Naoum, P.C. Eletroforese, técnicas e diagnósticos. São Paulo: Santos, 1998.
7. Papadea, C. \& Cate, J.C. Identification and qualification of hemoglobins A, F, S, and C by automated chromatography. Clin. Chem., 42: 57-63, 1996.

8. Schmidt, R.D. Laboratoy diagnosis of hemoglobinopathies. Jama, 224: 1276-80, 1973.

9. Schneider, R.G. Differentiation of electrophoretically hemoglobinssuchas S, D, G and P or A2, C, E, and O- by electrophoresis of the globin chains. Clin. Chem., 20: I I I -5, 1974.

10. Silvestroni, E. \& Bianco, I. Screening for microcytemia in Italy: analysis of data collected in the past 30 years. Am. J. Hum. Genet., 27: 198-212, 1975.

I I. Steinberg, M.H., Adams III, J.G. Laboratory diagnosis of sickling hemoglobinopathies. Southern Medical Journal, 71:413-6, 1978.

12. Vella, F. Acid agar gel electrophoresis of human hemoglobins. Am. J. Clin. Path., 49: 440, 1968.

I3. Weatherall, D.J. The thalassemia. Churchill Livingstone, 1983.

I4. Weatherall, D.J. \& Clegg, J.B. Genetic disorders of hemoglobin. Seminars in Hematology, 36: 24-37, 1999. 